\title{
A nasalização no português brasileiro pela teoria da otimidade
}

Elisa Battisti Universidade de Caxias do Sul

\section{Abstract}

The acceptance of the hypothesis of a / vN/ sequence as the basis of both nasal vowels and diphthongs, and the investigation of the nature of the nasal consonant in syllable coda, led us to relate subspecification of the nasal segment to the triggering of nasalization through the principles of Prosodic Licensing (Itô 1986,1989) and Autosegmental Licensing (Goldsmith 1990). Optimality Theory (Prince \& Smolensky 1993, McCarthy \& Prince 1993) conceives these principles as restrictions. The model predicts that the interaction of restrictions in a hierarchy determines the choice of the optimal form from a group of candidates generated by the grammar of a language for a given input. The conflict between Licence(place) and HavePlace chooses the homorganic NC sequence as one of the three possible optimal forms for the / vN/ sequence in word-internal position. In word-final position, the same two restrictions play a role in nasal glide formation from / oN/. The outcoming of a dissimilated peak-vowel is forced by MaxDist. 


\section{INTRODUÇÃO}

D ste artigo trata de dois fenômenos envolvidos na nasalização $\checkmark$ no português brasileiro, assimilação de ponto nasal-oclusiva e o surgimento do ditongo -ão, através de uma abordagem baseada em restrições, a Teoria da Otimidade (Prince \& Smolensky 1993, McCarthy \& Prince 1993). O objetivo é fornecer uma outra interpretação, possibilitada pelos recentes avanços nos modelos de análise fonológica, a processos amplamente tratado pelos lingüistas (Câmara Jr. 1953,1977,1984; Morais-Barbosa 1962; Madonia 1969; Saciuk 1970; Mateus 1975; Lipsky 1975; Lopez 1979; Parkinson 1983; Bisol 1989; Wetzels 1988,1997; Quicoli 1990; Lee 1995). O foco de atenção será transferido das regras fonológicas para restrições, que são reflexos de condições universais de boa-formação sobre representações.

Duas idéias são o ponto de partida da análise:

(a) a base de vogais - samba-e ditongos nasais - nação - é a mesma seqüência bimoraica /vN/, ${ }^{1}$ vN.C para as primeiras, vN\# $\#^{2}$ para os segundos;

(b) a subespecificação da nasal subjacente deve-se ao fato de a consoante ocupar posição de coda silábica (cf. Licenciamento Autossegmental, de Goldsmith 1990) e é o que desencadeia a nasalização (cf. Trigo Ferre, 1988).

\section{TEORIA DA OTIMIDADE}

\subsection{Princípios teóricos}

A Teoria da Otimidade procura responder a questões que dizem respeito à relação entre forma subjacente (input) e forma de superfície (output) e à atuação das restrições nesse mapeamento. 
Mostrar como um dado inputé emparelhado com o output correto e por que as restrições, em geral obedecidas, são violadas sob certas condições constitui, então, o objetivo da Teoria da Otimidade.

A resposta à primeira questão reside, segundo Prince \& Smolensky (1993) e McCarthy \& Prince (1993), na idéia, concebida ainda nos anos sessenta, de que os padrões lingüísticos são determinados por restrições estruturais que agem no nível de output. Uma importante característica dessas restrições é a sua generalidade. Formas que seriam geradas por regras de reescrita distintas podem ser associadas a uma única restrição, cuja atuação é a de impor limites às mudanças representacionais que, nessa nova concepção, ocorrem livremente.

Assim, a Teoria da Otimidade trabalha com a geração livre, a partir de uma forma de input (forma subjacente), de um conjunto de candidatos a output (forma de superfície). A escolha do output correto é feita através da avaliação da boa formação de cada um desses candidatos, tarefa desempenhada por um grupo de restrições relevantes.

A gramática, então, é configurada, pela Teoria da Otimidade, como segue:

$$
\begin{aligned}
& \text { Gen (in i) } \rightarrow \text { (cand } 1, \text { cand } 2, \ldots\} \\
& \text { Eval }(\{\text { cand } 1, \text { cand } 2, \ldots\})=\text { out real }
\end{aligned}
$$

(McCarthy \& Prince 1993, p.4)

Gen e Eval são duas funções da gramática. Gen é a abreviação do termo em inglês para 'gerador' (generator). De acordo com Prince \& Smolensky (1993), Gen é uma parte fixa da Gramática Universal que contém informações sobre primitivos representacionais e sobre relações universalmente irrevogáveis, como a de que o nó s (da sílaba) pode dominar o nó 'Onset', mas nunca o contrário. A tarefa de Gen é associar a cada input um conjunto, infinito, de análises gramaticais candidatas a output.

Eval, abreviação do termo inglês evaluation (avaliação), é uma função construída a partir das restrições (universais) de boa-formação. Sua tarefa é a de determinar a harmonia relativa dos candidatos 
produzidos por Gen, ordenando-os de acordo com o grau de satisfação às restrições: um output ótimo, aquele que melhor satisfaz as restrições de boa-formação, é posicionado por Eval no topo da ordem harmônica, formada pelo conjunto inteiro de candidatos avaliados. $^{3}$

O mapeamento input $\rightarrow$ output dá-se por processamento paralelo: todos os candidatos são produzidos de uma só vez por Gen e também de uma só vez, paralelamente, avaliados por Eval.

Antes de passar à exemplificação da atuação de Gen e Eval na produção e escolha do output ótimo, é importante abordar proprie-dades da Teoria da Otimidade que justificam sua proposta analítica.

\subsubsection{Propriedades do modelo da Teoria da Otimidade}

Na Teoria da Otimidade, restrição não é uma verdade fonotática válida apenas em um dado nível descritivo de uma língua. Uma restrição é um componente da Gramática Universal na medida em que corresponde a uma condição geral sobre estruturas.

Para Prince \& Smolensky (1993, p.2), o ponto fundamental a respeito das restrições é que elas não são mutuamente consistentes: as afirmações que fazem sobre a boa formação de representações são opostas, ou seja, conflitantes. Uma gramática é, então, segundo os autores, o modo como a língua resolve conflitos, elegendo condições de boa formação mais e menos importantes, isto é, hierarquizando-as. O modelo expressa tecnicamente o resultado dessa escolha através de hierarquias de dominância.

Nem todas restrições são necessariamente satisfeitas por um output. Com freqüência, a forma escolhida como ótima viola alguma restrição, normalmente dominada por outras restrições na hierarquia. A grande conseqüência de as restrições serem consideradas passíveis de violação é a inexistência de estratégias de reparo na Teoria da Otimidade: um output pode não ser estruturalmente perfeito, mas se, frente à hierarquia de restrições, for superior a outros candidatos, vem à superfície sem alteração. Então, o que existe na Teoria da 
Otimidade no lugar do reparo é a hierarquia de restrições, que acaba controlando a grau de violação através da noção de 'melhor satisfação' ao sistema de restrições conflitantes, o que pode significar a violação de uma restrição mais baixa na hierarquia para garantir a satisfação de outras em posições dominantes.

Deve-se salientar, contudo, que , embora permitida, a violação é sempre mínima: se todas as análises candidatas, produzidas por Gen, violarem restrições, vencerá aquela que apresentar o menor número de violações.

Os procedimentos de avaliação de candidatos e escolha de output pelas restrições, até aqui descritos, justificam a opção da Teoria da Otimidade pelo processamento paralelo: somente a comparação do desempenho de todos os candidatos ao mesmo tem-po pode apontar a melhor estrutura de superfície para dado input.

As gramáticas de todas as línguas são construídas com o mesmo conjunto de restrições (universais). O que determina a distinção entre as gramáticas individuais é o diferente ordenamento que tais restrições podem apresentar nas línguas. Assim, o modelo garante generalidade, característica que tem sido perseguida pela Gramática Gerativa em função de seu objetivo básico, que é o de afiliação à Gramática Universal.

Os aspectos da Teoria da Otimidade que acabaram de ser expostos foram resumidos em quatro propriedades por McCarthy \& Prince (1993) e por eles consideradas como 'marcas' do modelo:

(i) Violabilidade. As restrições são violáveis, mas a violação é mínima.

(ii) Ordenamento. As restrições são ordenadas com base em línguas particulares; a noção de violação mínima (ou melhor satisfação) é definida em termos desse ordenamento.

(iii) Inclusividade. As análises candidatas, que são avaliadas pela hierarquia de restrições, têm sua criação admitida por considerações muito gerais sobre boa formação estrutural; não há regras específicas ou estratégias de reparo com descrições estruturais específicas, nem mudanças estruturais conectadas a restrições específicas. 
(iv) Paralelismo. A melhor satisfação à hierarquia de restrições é calculada com base em toda a hierarquia e todo o conjunto de candidatos. (McCarthy \& Prince op.cit., p.5)

Um exemplo abstrato de análise pelo modelo permitirá que se verifiquem tanto suas propriedades, quanto o modo gráfico que adota para representar o processo de escolha dos candidatos.

\subsection{Procedimentos de análise}

Imagine-se uma língua $\mathbf{L}$ com uma gramática G. A tarefa de G é a de fazer o que se chama de 'mapeamento' de formas subjacentes a formas de superfície, formando pares: (inputa, outputa), (inpuđb, outputb), e assim por diante. Imagine-se, também, que G, para um input/in/ de L, gere dois candidatos, cand $\mathbf{1}$ e cand 2 . A escolha de um dos dois como output de /in/ é feita por Eval, função resultante do conflito de duas restrições, Res.x e Res.y, a respeito do conjunto de candidatos. Como em L a restrição Res.x é uma condição de boa formação de maior importância que Res.y, Res.x é a restrição dominante. Essa relação de dominância harmônica é representada simbolicamente por Res.x >> Res.y, e a forma ótima dentre \{cand $\mathbf{1}$, cand $\mathbf{2}\}$ é escolhida com base no melhor grau de satisfação às restrições em hierarquia. Isso implica que os candidatos sejam avaliados paralelamente, isto é, ao mesmo tempo, pois só a comparação do desempenho de cada um frente à hierarquia de restrições pode revelar qual deles apresenta melhor estrutura.

Imagine-se que, dos dois candidatos a output de /in/, cand $\mathbf{1}$ não violasse nenhuma das restrições envolvidas, cand2, apenas uma, a mais baixa na hierarquia. Cand $\mathbf{1}$ seria, nesse caso, considerado superior a cand $\mathbf{2}$ porque este incorreria em maior número de violações, mesmo em restrições hierarquicamente inferiores. Conforme procedimento gráfico adotado pela Teoria da Otimidade, esse, como todos os processos de escolha e avaliação, deve ser exposto num Tableau, termo francês para 'quadro'. O Tableau 1, a seguir, representa a hipotética avaliação recém descrita: 


\section{Tableau 1}

Input: /in/

\begin{tabular}{|c|c|c|c|}
\hline \multicolumn{2}{|c|}{ Candidatos } & Res.X & Res.y \\
\hline $\mathrm{a}$ & cand $\mathbf{1}$ & & \\
\hline b & cand 2 & & *! \\
\hline
\end{tabular}

A ordem de disposição das restrição no Tableau, da esquerda para a direita, reflete a relação de dominância na hierarquia. O símbolo é utilizado para indicar a forma ótima. Um asterisco (*) marca cada violação cometida pelos candidatos, e o ponto de exclamação (!) ao lado do asterisco salienta qual dentre as violações cometidas foi a responsável pela real eliminação do candidato, por essa razão denominada 'violação crucial'. No Tableau 1, o fato de cand 2 não ter satisfeito Res.y elimina-o crucialmente, uma vez que seu competidor, cand1, não produz nenhuma violação às restrições. Assim, cand1 é escolhido output de /in/.

Suponhamos agora um desempenho diferente de cand $\mathbf{1}$, forma ótima, frente à hierarquia de restrições, em que ele violasse restrições. Isso seria possível se, por exemplo, a forma concorrente, cand 2 , incorresse em violação à restrição dominante e cand1, à outra mais baixa na hierarquia, como mostra o Tableau 2. O sombreado é apenas um recurso para enfatizar a irrelevância da restrição, e das violações a ela cometidas, para o destino do candidato.

\section{Tableau 2}

Input: /in/

\begin{tabular}{|c|c|c|c|}
\hline \multicolumn{2}{|c|}{ Candidatos } & Res.x & Res.y \\
\hline$\Phi$ & cand $\mathbf{1}$ & & $*$ \\
\hline b. & cand 2 & $* !$ & \\
\hline
\end{tabular}


Cand1, mesmo não sendo estruturalmente perfeito, pois não satisfaz uma das restrições, Res.y, é escolhido output de /in/, porque Cand $\mathbf{2}$ viola a restrição mais alta. O contraste com o desempenho da análise concorrente, que viola a restrição dominante, é o que determina a escolha de Cand1, não o número de violações.

É possível, ainda, imaginar outra situação, em que um candidato fosse escolhido como ótimo, mesmo violando a restrição dominante. Isso só se verificaria em duas situações distintas: (a) caso o outro competidor também violasse a mesma restrição, mas em superior número de vezes, ou (b) se tanto a forma escolhida como a eliminada violassem em igual número de vezes a restrição dominante, mas a forma eliminada apresentasse, na soma de todas as outras violações a restrições inferiores na hierarquia, um maior número de violações. As situações (a) e (b), acima, são reproduzidas pelos Tableaux 3 e 4, respectivamente:

\section{Tableau 3}

Input:/in/

\begin{tabular}{|rr|c|c|}
\hline \multicolumn{2}{|c|}{ Candidatos } & Res.x & Res.y \\
\hline a. $\quad$ cand $\mathbf{1}$ & $*$ & \\
\hline b. $\quad$ cand $\mathbf{2}$ & $* * !$ & \\
\hline
\end{tabular}

\section{Tableau 4}

Input: /in/

\begin{tabular}{|rr|c|c|}
\hline \multicolumn{2}{|c|}{ Candidatos } & Res.x & Res.y \\
\hline a. $\quad$ cand $\mathbf{1}$ & $*$ & \\
\hline b. $\quad$ cand $\mathbf{2}$ & $*$ & $*$ \\
\hline
\end{tabular}

Os diferentes desempenhos imaginados para cand $\mathbf{1}$ e cand $\mathbf{2}$, acima, frente à hierarquia de restrições, expõem o princípio geral de avaliação sistemática que rege Eval, chamado simplesmente de 
Harmonia por Prince \& Smolensky (1993, p.3), e referido por McCarthy \& Prince (1993, p. 8) como Ordenamento Harmônico. Por esse princípio, a avaliação de dois candidatos se inicia pela comparação do número de marcas de violação à restrição mais alta na hierarquia que cada um produz. Se um deles apresentar mais violações que o outro, é eliminado. Se, no entanto, tal número de marcas for o mesmo, a avaliação prossegue com a análise do desempenho dos dois candidatos frente às restrições mais baixas na hierarquia. Esse procedimento vai impondo "uma ordem natural ao universo de candidatos, definindo a harmonia ou grau de sucesso relativo de cada candidato com respeito aos outros." (op. cit). Assim, da noção de melhor satisfação às restrições implicada pelo Princípio de Ordenamento Harmônico, faz parte um ordenamento de violações - viole a restrição mais baixa na hierarquia - e a garantia de violação mínima - viole cada restrição no menor grau possível.

Já os princípios que regem Gen não ficaram claros no exemplo anteriormente hipotetizado, e merecem, portanto, esclarecimento. A pergunta que se coloca é a seguinte: em que consiste o conjunto de candidatos que Gen gera e que Eval avalia? Para responder a tal questão, McCarthy \& Prince (op. cit.) expõem os princípios que seguem:

1. Liberdade de Análise. Qualquer quantidade de estrutura pode ser postulada.

2. Contenção. Nenhum elemento pode ser literalmente removido da forma de input. O input, portanto, está contido em toda forma candidata.

3. Consistência de Exponência. Nenhuma mudança na exponência de um morfema fonologicamente especificado é permitida. (McCarthy \& Prince op.cit.,p.20)

A aplicação dos dois primeiros princípios está interrelacionada. De acordo com Liberdade de Análise, Gen pode gerar todo tipo de candidato: com estrutura silábica, moraica e prosódica, com linhas de associação, segmentos, nós vazios ou completamente especificados para consoantes e vogais. Essa liberdade de criação de Gen 
seria ilimitada se não fosse a atuação conjunta do segundo princípio, Contenção, o qual impõe a obrigatoriedade da presença do input em qualquer candidato que Gen produza.

O terceiro princípio, Consistência de Exponência, garante que Gen não altere as especificações fonológicas de um morfema. Assim, segmentos epentéticos postulados por Gen, por exemplo, não possuem afiliação morfológica, mesmo que eles sejam limitados por um morfema ou estejam completamente contidos num morfema. Da mesma forma, a não-escansão de um segmento não muda um morfema, o que se altera é sua realização fonética: o segmento apenas deixa de ser pronunciado em nível de superfície, o que não implica seu apagamento na base. A idéia é, então, a de que quaisquer exponentes fonológicos de um dado morfema devam ser idênticos na forma subjacente e na de superfície, a menos que o morfema não possua especificações fonológicas, como, segundo McCarthy \& Prince (op.cit.), parece ser o caso dos morfemas reduplicativos.

Além dos três princípios acima, mais informação é necessária para que se compreenda a atuação de Gen. Gen pode, sim, gerar infinitas análises candidatas para um único input, mas sob uma condição: todas formas geradas devem ser lingüisticamente possíveis. Isso é garantido por postulados lingüísticos que especificam os tipos de estrutura que Gen pode criar. Esses postulados também permitem que sejam formuladas as restrições fonológicas em jogo em cada processo de avaliação e que se forneça uma interpretação para as representações das formas de output escolhidas. McCarthy \& Prince (op.cit.) esclarecem que tais postulados lingüísticos não são proposta exclusiva da Teoria da Otimidade: "são partilhados com muitas outras teorias da forma lingüística - são a base da maior parte da teoria fonológica contemporânea." (p.21). Como exemplo, citam, à mesma página, um postulado sobre a representação moraica:

[1] Representação Moraica. O nó da sílaba $(\sigma)$ pode dominar um ou dois nós de mora $(\mu)$. Cada nó de mora domina no máximo uma raiz segmental. As consoantes de onset são filhas de $\sigma$ : 

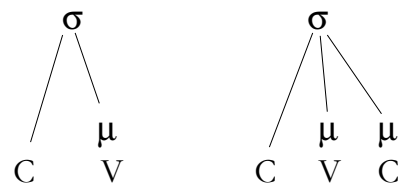

Em geral, um postulado como esse é introduzido nas análises sempre que seja importantes para a discussão e tratamento dos fenômenos estudados. O que merece relevo agora é o fato de essas informações lingüísticas, utilizadas por Gen e requisitadas pelo modelo, deixarem ainda mais clara a natureza da Teoria da Otimidade: não se trata de mais uma proposta de representação, uma teoria da sílaba ou da organização interna de segmentos. É um modelo sobre a gramática e seu funcionamento, que tem foco nas condições de boa formação representacional responsáveis pelo mapeamento de formas subjacentes a formas de superfície, isto é, pela emergência de um output a partir de um dado input. Os postulados lingüísticos de que lança mão não são, portanto, sua preocupação primeira, e devem ser entendidos como essenciais apenas na medida em que possibilitam propor restrições e interpretar representações. É por essa razão que adotar o modelo da Teoria da Otimidade significa, também, seguir o que no momento é 'consenso', nas diferentes subteorias ou módulos da fonologia não-linear, a respeito de postulados lingüísticos. Isso, e a aplicação do modelo à assimilação de ponto nasal-oclusiva e ao surgimento do ditongo -ão, é o que se verá nas próximas seções.

\section{ASSIMILAÇÃO DE PONTO NASAL-OCLUSIVA}

Nos termos de Itô, Mester e Padgett (1995), admite-se como afirmação explícita da conexão entre subespecificação da nasal/ assimilação de ponto de articulação e estrutura silábica a seguinte hipótese de Cancelamento de Licenciamento: se a nasal ocupa posição de coda da sílaba, seu traço de ponto de articulação não é licenciado. ${ }^{4}$ 
Conforme os autores, o cancelamento de licenciamento do traço de ponto de articulação de uma nasal em coda é forçado por um membro da família de restrições de licenciamento de traço, que esquematizam como:

\section{Licence $(\Phi)$}

O traço fonológico $\Phi$ deve ser licenciado.

(Itô, Mester \& Padgett op.cit., p.581)

Neste estudo, o membro da família de Licence em jogo é Licence (place):

\section{Licence (place)}

O traço de ponto de articulação deve ser licenciado.

A restrição Licence (place) é violada se a condição de licenciamento não é obedecida, o que ocorre, no caso em questão, se a nasal em coda silábica da forma candidata apresenta especificação para ponto de articulação. O efeito de Licence (place) é, então, o de pro-mover a subespecificação da consoante nasal em fim de sílaba.

O movimento oposto, requerendo a completa especificação da nasal, deve ser desempenhado por uma segunda restrição que reflita a implicação natural 'se é consoante, possui ponto de articulação (especificado)'. Clements e Hume (1995) observam que a necessidade de especificar o ponto de articulação de uma consoante deriva da própria definição de segmentos [+consonatal] ([-vocóide]) fornecida por Chomsky e Halle (1968) e tradicionalmente aceita: consoantes são sons produzidos com uma obstrução radical na região médio-sagital do trato vocal. "Sons sem traços de ponto orais não podem ter tal obstrução, e são, então, necessariamente nãoconsonantais" (Clements a Hume 1995, p.271). Um segmento que perde ponto de articulação, então, se realiza como um glide [-consonantal] ([+vocóide]). No modelo da Geometria de traços, essa especificação de ponto de articulação de uma consoante corresponde à realização do nó 'Pontos de C'.

Padgett (1995d) propõe que tal condição para a realização das consoantes reflita-se na restrição HavePlace (TenhaPonto): 
HavePlace: Todo segmento deve ter algum ponto

Para todo segmento S, $\exists \mathrm{x}, x \in$ Ponto, $x(\mathrm{~S})$

(Padgett op.cit., p.6)

$\mathrm{Na}$ formalização da restrição, S representa 'segmento', $x$ representa 'traço' e $x(\mathrm{~S})$ significa que o traço $x$ está contido no segmento $S$.

Um segmento sem ponto de articulação especificado incorre em violação a HavePlace. É o que se dá com uma nasal sem ponto em coda silábica, situação desejada por Licence, mas banida por HavePlace. Tem-se, então, um conflito entre as duas restrições. Os dois candidatos à realização de samba, abaixo, exemplificam a relação conflitante:
(a) samba
* Licence (place)
(b) saNba
$\checkmark$ Licence
$\checkmark$ HavePlace
*HavePlace
[labial]

Cada um dos candidatos viola uma das restrições e satisfaz a outra: (a) traz a nasal especificada por [labial], como HavePlace exige, mas contra o que Licence (place) demanda, uma vez que aquela consoante, em final de sílaba, não tem licenciado seu traço de ponto de articulação; (b) apresenta a nasal na coda sem ponto, estando de acordo com Licence (place), mas violando HavePlace por estar sem especificação.

O empate é desfeito quando as formas são avaliadas pelas restrições numa hierarquia: vence o candidato que viola menos, ou não viola, restrições em posições mais altas na hierarquia. Cabe-nos, então, posicionar Licence (place) e HavePlace nessa relação de dominância. Supomos, para o estudo em questão, que Licence (place) domine HavePlace, como abaixo:

\section{Licence $($ place $)>>$ HavePlace}

O Tableau 5 mostra graficamente a avaliação dos candidatos (a) e (b): 


\section{Tableau 5}

\begin{tabular}{|cr|c|c|}
\hline \multicolumn{2}{|c|}{ Candidatos } & Licence (place) & HavePlace \\
\hline a. & saNba & & $*$ \\
\hline b. & $\begin{array}{c}\text { samba } \\
\text { [labial] }\end{array}$ & & \\
& & & \\
\hline
\end{tabular}

O candidato (a), acima, vence o conflito, mesmo não satisfazendo HavePlace, porque a forma rival, (b), viola a restrição mais alta na hierarquia, Licence (place). A implicação imediata de tal desfecho é a idéia de que a forma de output pode não corresponder a um candidato perfeito, que não incorra em nenhuma violação, mas se origine daquele que melhor satisfizer o conjunto de restrições, produzindo violações em menor número e mais baixas na hierarquia.

Voltando às formas (a) e (b) e à avaliação no Tableau 5, percebe-se que o candidato vencedor, (a), apresenta nasal em coda subespecificada, o que não corresponde ao output dessas consoantes em português. Como vimos, uma consoante sem ponto se realiza como um glide, isto é, como um segmento [-consonantal] ([+vocóide]), resultado indesejado em interior de vocábulo. Poderse-ia pensar que o problema reside no ordenamento das restrições na hierarquia: HavePlace deveria dominar Licence (place), originando um vocábulo com nasal em final de sílaba especificada para ponto de articulação:

\section{Tableau 6}

\begin{tabular}{|cc|c|c|}
\hline \multicolumn{2}{|c|}{ Candidatos } & HavePlace & Licence(place) \\
\hline a. & saNba & $* !$ & \\
\hline b. & $\begin{array}{c}\text { samba } \\
\text { [labial] }\end{array}$ & & \\
& & & \\
\hline
\end{tabular}


Esse resultado, contudo, também não é o que se espera das nasais em coda em português. Por todas as razões apontadas pela literatura sobre o assunto, tais consoantes em final de sílaba não apresentam ponto de articulação, assimilam-no da oclusiva seguinte e, algumas vezes, da vogal precedente, o que está intimamente relacionado ao espraiamento de [nasal] e nasalização da vogal. Além disso, o candidato (b), que aparece como vencedor no Tableau 6 , seria excluído por OCP. ${ }^{5}$

Isso sugere, ao invés da modificação na ordem das restrições na hierarquia, a existência de um terceiro candidato, gerado por Gen, com características diferentes de (a) e (b). Mantendo-se a dominância de Licence (place) sobre HavePlace e seguindo a idéia de Itô, Mester e Padgett (1995) para a assimilação de [sonoro] em encontros de nasal e oclusiva no japonês, propomos um terceiro candidato com dupla ligação para ponto de articulação:

\section{Tableau 7}

\begin{tabular}{|c|c|c|c|}
\hline \multicolumn{2}{|c|}{ Candidatos } & Licence (place) & HavePlace \\
\hline a. & saNba & & $*$ \\
\hline $\mathrm{b}$ & $\underset{\text { [labial] }}{\text { samba }}$ & $* !$ & \\
\hline C. & samba & & \\
\hline
\end{tabular}

A nasal do candidato (c ) assimila o traço de ponto, [labial], da consoante seguinte, operação representada por linhas pontilhadas no Tableau 7. Dessa forma, o traço [labial], embora não licenciado pela coda para a consoante nasal, é licenciado pela oclusiva seguinte porque esta se localiza em posição de onset silábico, satisfazendo Licence (place). A conseqüência de tal partilha de traço é a emergência do candidato (c ) como forma ótima, já que nenhuma das restrições em jogo é por ele violada. 
A forma de output com dupla ligação retrata adequadamente a relação de homorganicidade que pode se estabelecer entre nasal e oclusiva no português. ${ }^{6}$ A hierarquia de restrições com Licence (place) dominando HavePlace, por sua vez, produz o resultado correto do condicionamento prosódico exercido pela sílaba sobre os segmentos consonantais em coda silábica. Essas são respostas bastante adequadas aos fatos do português.

No entanto, nem todas as questões relativas à assimilação de ponto nasal/oclusiva estão resolvidas. Resta, ainda, abordar um aspecto importante que é o da forma de input considerada por Gen para produzir o conjunto de candidatos avaliados pelas restrições. Isso se faz necessário porque, pelo modelo da Teoria da Otimidade, formas de input e de output devem ser maximamente correspondentes, e o candidato a output aqui sendo considerado como ótimo resulta de uma operação autossegmental (espraiamento de traço) que, dependendo do input, pode estar apresentando um grau indesejado de modificação.

De acordo com Prince e Smolensky (1993), o papel de limitar as discrepâncias entre formas de inpute de outputé desempenhado por uma família de restrições chamada Faithfulness ('Fidelidade'). A existência de Faithfulness se justifica porque Gen pode produzir toda uma gama de 'improvisos' de output, correspondentes a possíveis resultados de diferentes operações fonológicas. Ao lado de outras restrições na hierarquia, Faithfulness age sobre Gen, avaliando o maior ou menor distanciamento entre input e output e garantindo um grau máximo de boa formação às estruturas geradas pela gramática.

De Faithfulness fazem parte duas restrições, Parse e Fill ('Escanda' e 'Preencha'). Parse exige que os elementos sejam escandidos, isto é, sejam dominados por um nó apropriado da árvore prosódica, no que reflete o Licenciamento Prosódico de Itô $(1986,1989)$. "Parse-seg requer que os segmentos pertençam à estrutura silábica ou moraica; Parse- $\mu$ requer que um mora $\mu$ seja dominada por $\sigma$, o nó silábico; Parse- $\sigma$, que sílabas pertençam a pés, 
e assim por diante" (McCarthy \& Prince, 1993,p.14). O papel de Parse é evitar que 'stray erasure', ou apagamento do elemento perdido, elimine segmentos presentes no input por falta de afiliação à estrutura prosódica.

Fill proíbe o aparecimento, no output, de elementos que não façam parte do input. Tal inserção dar-se-ia se houvesse posições silábicas vazias na forma candidata, a serem foneticamente preenchidas por elementos epentéticos. Fill não quer isso, quer que todas as posições na forma candidata estejam preenchidas. Assim, outra leitura de Fill pode ser a de que todos os nós devem dominar suas respectivas filhas.

Itô, Mester e Padgett (1995) acreditam que Faithfulness deva cobrir tanto substância quanto estrutura. Entendem que essa família de restrições deva governar não apenas macroelementos, como segmentos inteiros, mas também traços individuais e relações de associação entre traços. Chegam, dessa forma, à seguinte ampliação de Faithfulness, em que feature significa 'traço' e link, 'ligação':

\section{FAITH (Feature Faithfulness)}

ParseFeat

Todos os traços de input são escandidos.

FillFeat

Todos os traços são parte do input.

ParseLink

Todas as relações de associação de input são mantidas. FillLink

Todas as relações de associação são parte do input.

(Itô, Mester \& Padgett op.cit., p.586)

Pela Teoria da Otimidade, todas as gramáticas possuem Faithfulness. Trata-se de um conjunto de restrições universais, como o modelo prevê que sejam todas as restrições. Faithfulness pode ser violada numa relação de conflito com outras restrições, superiores na hierarquia, proibindo certas realizações de output. Gen pode, dessa forma, inserir novas estruturas ou traços, ou falhar na escansão de traços ou estruturas do input, violando Fill e Parse, mas satisfa- 
zendo restrições que dominam Faithfulness na gramática de dada língua. Nesse caso, segundo Itô, Mester e Padgett (op.cit.), a função de tal família de restrições acaba sendo a de atribuir um custo, por exemplo, a operações autossegmentais de inserção, espraiamento ou apagamento de traço, sem, contudo, impedir que elas ocorram.

A exemplo do trabalho dos autores, supõe-se que Faithfulness seja dominada por outras restrições também em português. No caso em questão, Licence (place) e HavePlace dominam Faithfulness:

Licence $($ place $) \gg>$ HavePlace $>>$ Faithfulness

A hierarquia acima é utilizada para avaliar formas alternativas de input frente ao conjunto de candidatos gerados por Gen. Os inputs do vocábulo samba avaliados são (a) e (b) abaixo, com a nasal especificada e subespecificada, respectivamente, para ponto de articulação:
(a) /samba/
(b) /saNba/

[lab]

Os Tableaux 8 e 9 mostram o resultado da avaliação dos inputs frente a possíveis outputs:

\section{Tableau 8}

Input: /samba/

[lab]

\begin{tabular}{|c|c|c|c|}
\hline Candidatos & Licence (place) & HavePlace & Faithfulness \\
\hline $\begin{array}{ll}\text { a. } & \text { samba } \\
& \text { [lab] }\end{array}$ & $* !$ & & \\
\hline $\begin{array}{c}\text { b. samba } \\
\neq \\
{[\mathrm{lab}]}\end{array}$ & & $* !$ & $*$ \\
\hline $\begin{array}{cc}\text { c. } & \text { samba } \\
\neq \\
\\
{[l a b]}\end{array}$ & & & $* *$ \\
\hline
\end{tabular}




\section{Tableau 9}

Input: /saNba/

\begin{tabular}{|c|c|c|c|}
\hline Candidatos & Licence (place) & HavePlace & Faithfulness \\
\hline a. saNba & & $* !$ & \\
\hline b. & $* !$ & & * \\
\hline c. samba & & & * \\
\hline
\end{tabular}

O primeiro aspecto significativo revelado pela avaliação é o de que a dominância de Licence (place) e HavePlace sobre Faithfulness produz o output correto, mesmo que este contenha violações à Faithfulness. No Tableau 8, a forma ótima, (c), viola duplamente Faithfulness porque a nasal é contexto de duas operações autos-segmentais, apagamento e espraiamento de traço. Mesmo assim é superior aos outros dois candidatos, (a) e (b), porque satisfaz as restrições que dominam Faithfulness na hierarquia. Da mesma forma, no Tableau 9, a forma de output, (c), distingue-se da de input porque uma operação de espraiamento de traço forneceu especifica-ção de traço [labial] para a nasal, o que constitui violação de Faithfulness. Ainda assim, (c) é o candidato vencedor porque satisfaz Licence (place) e HavePlace, restrições mais altas na hierarquia.

O segundo aspecto, e mais importante, é o de que não importa se a configuração de input traz a nasal especificada ou subespecificada. Como se vê comparando os Tableaux 8 e 9, mantida a hierarquia de restrições em que Licence domina Faithfulness, a forma com dupla ligação para ponto de articulação será sempre a escolhida. Esse efeito de subespecificação é, segundo Itô, Mester e Padgett (op.cit), conseqüência da própria dinâmica prevista pelo modelo da Teoria da Otimidade: os efeitos de subespecificação são 
efeitos de output, e dependem unicamente da hierarquia de restrições Licence >> Faithfulness. "Subespecificação é, então, uma emergente propriedade do output" (op.cit., p.589).

Esse resultado, o de que não importa o grau de especificação do input, parece desfazer a necessidade, tradicionalmente comprovada, de fornecer argumentos para sustentar a tese de que a nasalidade contrastiva em interior de vocábulo deriva, em português, da seqüência subjacente nasal-sem-ponto + consoante. No entanto, é possível continuar a admitir nasal subespecificada como origem da nasalidade em português. O Tableau 10, um "Tableau des Tableaux"(Itô, Mester e Padgett 1995, p.593), ajudará a esclarecer as razões que levam a explorar tal possibilidade. Nele, são comparadas as formas vencedoras nos Tableaux 8 e 9:

\section{Tableau 10}

\begin{tabular}{|c|c|c|c|c|}
\hline Input & Output & Licence (place) & HavePlace & Faithfulness \\
\hline a. /samba/ & $\begin{array}{c}\text { samba } \\
=\vdots \\
{[1 \mathrm{ab}]}\end{array}$ & & & $* *$ \\
\hline b. / $/ \mathrm{saNba} /$ & $\begin{array}{c}\text { samba } \\
\vdots \\
{[l a b]}\end{array}$ & & & $*$ \\
\hline
\end{tabular}

Como se percebe claramente, o output da forma de input em (b), com nasal subespecificada, incorre em apenas uma violação à Faithfulness, uma vez que ocorre apenas o espraiamento do traço de ponto de articulação da oclusiva para a nasal. Já o output do input (a) apresenta duas violações, correspondentes às operações de desligamento e espraiamento de traço. Em outras palavras, input e output em (b) são menos discrepantes. O input (b), então, emerge como o input ótimo para o output com dupla ligação.

Eis aí um papel fundamental desempenhado por Faithfulness, o de escolher, entre vários inputs que convergem para um mesmo 
output núcleo, o mais harmônico. É importante salientar que essa avaliação de harmonia relativa não é, de acordo com Prince e Smolensky (1993, p.192), um procedimento técnico, apenas. Tratase da conseqüência de um princípio que os autores chamam de Otimização Lexical ('Lexicon Optimization'), parafraseado por Itô, Mester e Padgett (1995, p.593) como segue:

"Otimização Lexical

De vários inputs potenciais cujos outputs convergem, todos, para a mesma forma fonética, escolha como input real aquele cujo outputé o mais harmônico."

Prince e Smolensky (1993) explicam que o Princípio da Otimização Lexical tem relação com as inferências que o aprendiz da gramática de uma língua deve fazer ao mapear os outputs por ele ouvidos aos inputs correspondentes. Os autores acreditam que as relações mais facilmente estabelecidas e aprendidas são aquelas que incorrem em um menor número de marcas de violação, sendo consideradas, por essa razão, as mais harmônicas.

É por isso que a questão sobre a forma subjacente de vogais nasais em português é resolvida em favor da estrutura subespecificada. A gramática seleciona o input que mostra melhor comportamento frente à dupla ligação entre nasal e oclusiva, forma de output que os encontros NC necessariamente apresentam para traço de ponto de articulação em português.

\section{O SURGIMENTO DO DITONGO -ão}

Como vimos, consoantes nasais em final de sílaba não têm licenciado seu traço de ponto de articulação justamente por ocuparem posição de coda silábica. Essa subespecificação, relacionada à estrutura prosódica, satisfaz à restrição Licence (place).

Em interior de vocábulo, a nasal pode obter especificação para traço de ponto de articulação assimilando-o da consoante seguinte. Nesse caso, não há violação a Licence (place) porque a oclusiva no onset da sílaba seguinte licencia o traço de ponto de articulação. A 
configuração com partilha de traço, então, é o que satisfaz Licence (place) e possibilita que a nasal se manifeste em nível de superfície.

Em posição final de vocábulo, não há consoante seguinte que empreste seu traço de ponto de articulação à nasal. A ausência de um nó de ponto determina que esse segmento, que, na subjacência, corresponde apenas ao nó de raiz ao qual se liga o traço [+nasal], se superficialize necessariamente como [+vocóide], um glide. ${ }^{7}$

Dessa forma, a hipótese que se segue para tratar do surgimento do ditongo -ãoé a de que a base dos ditongos nasais é uma seqüência vN\#. A restrição de licenciamento (prosódico) autosseg-mental impede que a nasal adquira especificação para ponto de articulação e, na ausência de uma consoante seguinte que possa emprestar tal traço à nasal, força a emergência de um glide nasal, o anusvara de Ferre (1988).

A escolha de -ão como único ditongo nasal cuja criação será aqui analisada deve-se à sua grande produtividade no atual estágio do português brasileiro e às regularidades que os paradigmas envolvendo tal ditongo apresentam (cf. Battisti 1997). A relação

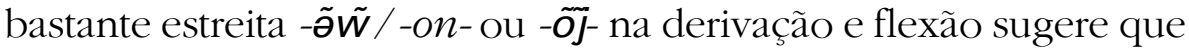

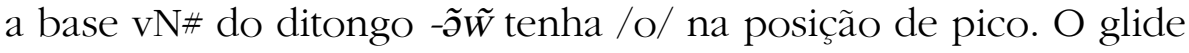
posterior é o próprio anusvara que, sem traço de ponto de articulação de consoante, vem à superfície como [+vocóide], e assimila traço de ponto de articulação da vogal que o precede. Admitir essa hipótese significa ter que explicar dois aspectos pela Teoria da Otimidade: o surgimento do glide posterior e a formação do ditongo dissimilado pela alteração da qualidade da vogal-pico. É o que faremos nas próximas duas seções.

\subsection{A emergência do glide nasal posterior}

As restrições que atuam no surgimento do glide posterior nasal são Licence(place) e HavePlace, já apresentadas na seção 3. A título de clareza, ambas serão retomadas a seguir: 
Licence (place)

O traço de ponto de articulação deve ser licenciado.

(cf. Itô, Mester \& Padgett 1995d, p.581)

HavePlace

Todo segmento deve ter algum ponto.

(Padgett 1995d, p.6)

A restrição Licence (place) força o cancelamento do licenciamento de traço de ponto de articulação da consoante nasal em coda silábica. HavePlace, ao contrário, é uma restrição que exige a especificação de ponto para qualquer segmento, seja ele vogal ou consoante, sob pena de tal elemento não poder se realizar em nível de superfície.

Na gramática que gera o ditongo -ão a partir de vN\#, Licence (place) domina HavePlace, fazendo com que a nasal sem ponto de articulação seja o candidato escolhido. Assim, se somente Licence (place) e HavePlace atuassem na avaliação dos candidatos a output de vN\#, a nasal de base não apresentaria qualquer tipo de manifestação em superfície, a não ser sua nasalidade, espraiada à vogal. A idéia aqui perseguida, no entanto, é a de que o glide posterior do ditongo -ão deriva da nasal subjacente. Uma terceira restrição, então, deve estar em jogo, garantindo que material segmental não se perca. Essa restrição é Parse.

Como vimos (seção 3), Parse luta pela manutenção de todo material subjacente: traços, moras, segmentos, sílabas. Apagamento da nasal de base constitui, então violação a Parse. Nesse sentido, Parse difere de HavePlace, que requer apenas que a especificação faça parte do output, não importando se o material está presente no input e, dessa forma, deva ser escandido, ou se ele está ausente no input e tenha de ser assimilado ou inserido. Assim, a não inserção de traço de ponto na nasal, que causa o apagamento da consoante, constitui violação também a HavePlace. Na hierarquia que faz surgir -ão, então, Parse e HavePlace não dominam um ao outro: 
A avaliação de três candidatos e a escolha da forma com glide nasal como output ótimo são mostradas no Tableau 11.

\section{Tableau 11}

Input: vN\#

\begin{tabular}{|lc|c|c|}
\hline & Candidatos & Licence (place) & HavePlace, Parse \\
\hline a. & $\tilde{\mathrm{v} N}$ & & $* ! *$ \\
& $\downarrow$ & & \\
& $\varnothing$ & & \\
\hline b & $\mathrm{vn}$ & $* !$ & $* ! *$ \\
\hline c. $\quad \tilde{\mathrm{v}} \tilde{\mathrm{W}}$ & & \\
& & & \\
& {$[$ ponto] } & & \\
\hline
\end{tabular}

No candidato (a), a nasal não recebe traço de ponto de articulação e é apagada, apenas emprestando seu traço [nasal] à vogal. (a) satisfaz Licence (place), mas viola HavePlace por não ter recebido especificação de traço de ponto, e Parse, porque acaba não se realizando em superfície. O candidato (c) apresenta a nasal em coda com ponto, o que permite que ela se superficialize, satisfazendo ambas HavePlace e Parse, mas violando Licence (place), restrição mais alta na hierarquia, razão pela qual é eliminado. A forma em (c) emerge como ótima porque o anusvara, na ausência de consoante seguinte, perde sua natureza consonantal, mas se realiza, como glide, com a qualidade que assimila da vogal precedente, satisfazendo todas as restrições. Novamente a partilha de traço é a solução quando, na gramática, Licence é a restrição dominante.

É um glide, $\tilde{w}$, e não outro vocóide que surge da nasal de base porque, em português, somente glides podem ocupar posição póspico, o que implica preenchimento automático do nó de abertura com as especificações [-ab1,2,3]. E, dos dois glides possíveis em português, /j, w/, o posterior é o que surge porque, admitindo-se oN\# como base de - $\tilde{\boldsymbol{a}} \boldsymbol{o}$, os traços [dorsal] e [labial] da vogal-pico são absorvidos pelo segmento nasal. 


\subsection{A formação de ditongo dissimilado a partir de /oN/}

Como foi dito na introdução à seção, admite-se como base de -ão a seqüência oN\#. Explicado o surgimento do glide posterior, é preciso abordar a mudança de qualidade da vogal-pico, que passa de /o/ para [ã], quando da formação do ditongo. Trata-se de um processo de ditongação dissimilatória que não é exclusividade do português.

Sluyters (1992) aborda processos de ditongação dissimilatória em dialetos do italiano. Nos sistemas de que trata, as duas partes de uma vogal (longa) ditongada tornam-se distintas para posterioridade e arredondamento. A vogal-pico adquire especificações para traço de ponto que são diferentes daquelas da vogal subjacente. Em um dialeto chamado Pozzuoli, por exemplo, as seguintes são possibilidades de ocorrência:

\begin{tabular}{|c|c|}
\hline sola] & $\rightarrow \quad$ ['saula] \\
\hline [seta] & ['saita] \\
\hline una] & $\rightarrow \quad$ ['leuna] \\
\hline
\end{tabular}

(Sluyters op.cit.,p.35)

Esses ditongos são criados em contexto de alongamento da vogal que ocupa posição tônica nos vocábulos. Ou seja, o condicionamento é prosódico.

A qualidade da vogal-pico do ditongo pode, em alguns casos, ser prevista a partir da vogal subjacente. É o que se verifica em Palmoli, outro dialeto do italiano: se a vogal de base é média, uma vogal baixa se manifesta na posição de pico:

\begin{tabular}{rll} 
/o:/ & $\rightarrow$ & {$[$ au] } \\
['sola] & $\rightarrow$ & ['saula] 'sozinha' \\
['kot]a] & $\rightarrow$ & ['kautfa] 'cozinhar' \\
& \multicolumn{3}{c}{$\quad$ (Sluyters op.cit., p.37; 198) }
\end{tabular}

O autor explica que a primeira metade de uma vogal média longa sofre abaixamento de um grau. Como, em Palmoli, a única vogal [+baixo] é /a/, só essa pode ser a vogal que se manifesta 
ocupando pico no ditongo que se forma a partir da média longa / o:/. É por essa razão que o autor interpreta o processo de abaixamento da vogal-pico como expressão de uma restrição particular a dada língua, dependente do inventário fonêmico da mesma.

Em português, devido à impossibilidade de a nasal subespecificada em final de vocábulo adquirir ponto de articulação de consoante seguinte, a seqüência candidata a outputé necessariamente formada por dois segmentos [+vocóide]. Como vimos na seção anterior, o vocóide pós-pico só pode ser um glide, e posterior, por assimilação da qualidade da vogal-pico, criando um ambiente que se assemelha ao de vogal longa. Dessa forma, é possível dizer que, a exemplo da dissimilação nos dois dialetos do italiano, o português promove a distinção dos vocóides do input /oN/ provocando alterações na vogal-pico ou primeira metade do ditongo. O contexto para essa dissimilação é o de nasalização.

A modificação de /o/ se dá pela não escansão do traço de ponto [labial], em violação a Parse-feat ("Todos os traços de input são escandidos", ver seção 5.1.1). Assim, no pico da seqüência oN\#, /o/ passa a /a/, que se realiza como [ã] quando nasalizado. Abaixo, somente a dissimilação promovida por Gen:

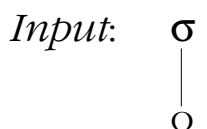

Output:

$\mathrm{O}$

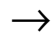

a
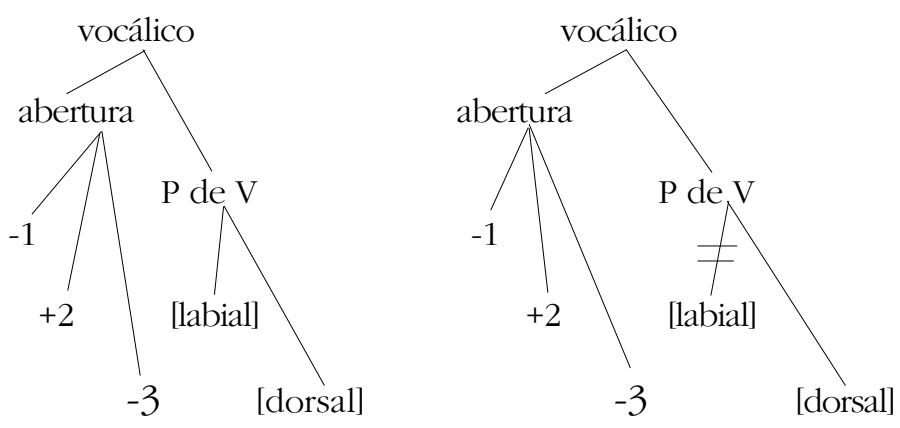
Para que [ãw̃ seja escolhido como forma ótima, Parse-feat, então, precisa ser dominado na hierarquia de restrições. Propõe-se que as restrições em jogo sejam Parse-feat que, como vimos, força a escansão dos traços que são parte do input, e uma restrição que será chamada de MaxDistinção, militando a favor da máxima distinção entre as duas partes do ditongo:

MaxDistinção (MaxDist)

A constrição de V-pico subjacente e V-pico de superfície é maximamente distinta.

MaxDist domina Parse-feat: MaxDist >> Parse-feat. O Tableau 12 traz a avaliação de dois candidatos:

\section{Tableau 12}

Input: oN\#

\begin{tabular}{|c|c|c|}
\hline Candidatos & Max Dist & Parse-feat \\
\hline 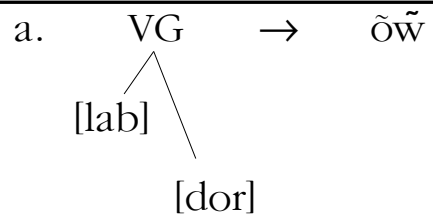 & $* !$ & \\
\hline b. $\underbrace{\mathrm{VG}}_{[\mathrm{dor}]} \rightarrow \tilde{\mathrm{e}} \tilde{\mathrm{W}}$ & & $*$ \\
\hline
\end{tabular}

O candidato (a) é uma das possibilidades de manifestação da seqüência oN\# subjacente, mas não se realiza quando a restrição Max Dist domina Parse-feat na hierarquia. Nessa ordem, vence o candidato (b), com vogal-pico maximamente distinta de sua base pela não escansão do traço [labial]. A inversão na hierarquia pela localização de Parse-feat acima de MaxDist é, então, o que leva à seleção de [õ̃̃] como forma ótima, o que explica a possibilidade de dupla pronúncia em vocábulos como garçon/garção, edredon/ edredão, bom/bão. ${ }^{8}$ 


\section{CONCLUSÃO}

O modelo da Teoria da Otimidade permitiu mostrar que tanto a assimilação de ponto nasal-oclusiva quanto o surgimento do ditongo -ão são determinados, no português brasileiro, pela interação (antagônica) de restrições.

Licence(place) e HavePlace militam, respectivamente, pela subespecificação e especificação da nasal em coda silábica. Em português, como em outras línguas, Licence(place) domina HavePlace. A solução do conflito leva à partilha de traço entre oclusiva seguinte, em onset silábico e, por essa razão, especificada para ponto de articulação, e nasal, determinando a escolha do candidato com nasal homorgânica à oclusiva como forma ótima.

No surgimento do ditongo -ão, Licence(place) e HavePlace também entram em jogo: são responsáveis pela emergência do glide nasal. Na gramática em que Licence(place) domina HavePlace, a nasal em coda no final de vocábulo também não recebe traço de ponto e, não tendo consoante seguinte com que possa partilhar traço, emerge como glide nasal. Ao mesmo tempo, a vogal-pico, por força de MaxDist, que requer distinção máxima entre vogal e semivogal, determina a escolha do candidato com vogal-pico dissimilada como forma ótima. A opção de tratar os processos via restrições, e não regras, mostrou como a interação de razões lingüisticamente distintas determina as escolhas realizadas pelo falante, esclarecendo ainda mais uma peculiaridade tão saliente em nossa língua, que são os padrões de nasalidade.

\section{REFERÊNCIAS BIBLIOGRÁFICAS}

BATTISTI, Elisa. A nasalização no português brasileiro e a redução dos ditongos nasais átonos: uma abor dagem baseada em restrições. Porto Alegre, 1997. Tese (Doutorado em Lingüística Aplicada) - Instituto de Letras, Pontifícia Universidade Católica do Rio Grande do Sul.

BISOL, Leda. O ditongo na perspectiva da fonologia atual. D.E.L.T.A., v.5, n.2,1989. p. $185-224$. 
CÂMARA JR., Joaquim Mattoso. Para o estudo da fonêmica portuguesa. Rio de Janeiro: Organização Simões, 1953. . Estrutura da lingua portuguesa. 8.ed. Petrópolis: Vozes, 1977. . Problemas de lingüística descritiva. 11.ed. Petrópolis: Vozes, 1984.

CHOMSKY, Noam \& HALLE, Morris. The sound pattern of English. Nova Iorque: Harper \& Row, 1968.

CLEMENTS, G.N. \& HUME, E.V. The internal organization of speech sounds. In: GOLDSMITH, John A.(editor) The handbook of phonological theory. Cambridge, Mass./Oxford: Blackwell, 1995.

FERRE, Rosario L. T. On the phonological behavior and derivation of nasal glides. Cambridge, Mass., 1988. Tese (Doutorado em Lingüística) - Instituto de Tecnologia de Massachusetts (MIT).

GOLDSMITH, J.A. Autosegmental \& metrical phonology. Oxford: Blackwell, 1990. ITÔ, Junko. Syllable theory in prosodic phonology. Massachusetts, 1986. Tese (Doutorado em Lingüística) - Departamento de Lingüística, Universidade de Massachusetts.

A prosodic theory of epenthesis. Natural language and linguistic theory 7. p. $217-259,1989$.

ITÔ, J.; MESTER, A.; PADGETT, J.. Licensing and underspecification in optimality theory. Linguistic Inquiry, v. 26, n. 4, outono 1995. p. 571-613.

LEBEN, William. Suprasegmental phonology. Cambridge, Mass., 1973. Tese (Doutorado em Lingüística) - Instituto de Tecnologia de Massachusetts (MIT).

LEE, Seung-Hwa. Morfologia e fonologia lexical do Português do Brasil. Campinas, 1995. Tese (Doutorado em Lingüística) - Universidade Estadual de Campinas.

LIPSKY, John M. Brazilian Portuguese vowel nasalization: secondary aspects. The Canadian Journal of Linguistics 20:1. p. 59-77, Spring 1975.

LOPEZ, Barbara S.. The sound pattern of Brazilian Portuguese (Cariocan Dialect). Los Angeles, 1979. Tese (Doutorado em Lingüística) - Universidade da Califórnia em Los Angeles.

MADONIA, Giovanna. Les diphthongues décroissantes et les voyelles nasales du portugais. La Linguistique 3. p. 129-132, 1969.

McCARTHY, John \& PRINCE, Alan. Prosodic morphology I - constraint interaction and satisfaction. (não-publicado). Amherst/New Brunswick, Universidade de Massacusetts e Universidade de Rutgers, 1993.

MATEUS, Maria Helena M.. Aspectos da fonologia potuguesa. Lisboa: Centro de Estudos Filológicos, 1975. 
MORAIS-BARBOSA, Jorge. Les voyelles nasales portugaises: interprétation phonologique. In: PROCEEDINGS OF THE FOURTH INTERNATIONAL CONGRESS OF PHONETIC SCIENCES (4-9 Setembro 1961) Haia, 1962. p.691709.

PADGETT, Jaye. Partial class behavior and nasal place assimilation. In: COYOTE WORKING PAPERS. Proceedings of the Arizona Phonology Conference: workshop on features in Optimality Theory. Tuscon, Universidade do Arizona, 1995d. p.1-40. (não-publicado)

PARKINSON, Stephen. Portuguese nasal vowels as phonological diphthongs. Lingua 61. p. 157-177, 1983.

PRINCE, Alan \& SMOLENSKY, Paul. Optimality theory: constraint interaction in generative grammar. (não-publicado) New Brunswick/Boulder: Universidade de Rutgers e Universidade do Colorado, 1993.

QUICOLI, A. Carlos. Harmony, lowering and nasalization in Brazilian Portuguese. Lingua 80, p.295-331, 1990.

SACIUK, Bohdan. Some basic rules of Portuguese phonology. In: SADOCK, J.M. \& VANEK, A.L.(editores). Studies presented to Robert B. Lee by his students. Champaign: Linguistic Research Inc., 1970. p. 197-222.

SLUYTERS, W.A. M. Representing diphthongs. Nijmegen, 1992. Tese (Doutorado em Lingüística) - Universidade Católica de Nijmegen.

TLÁSKAL, Jeromír. Remarques sur les voyelles nasales en portugais. Zeitschrift für Phonetik 33. p. 562-570, 1980.

WETZELS, W. Leo. Contrastive and allophonic properties of Brazilian Portuguese vowels. (a ser publicado) In: WANNER, D. \& KIBBEE, D.A. Selected papers from the Linguistic Symposium on Romance Languages 18. Amsterdã: Benjamins, 1988. p. 1-26.

. The lexical representation of nasality in Brazilian Portuguese. Probus. fev., 1997. p. 01-34. (versão pré-final).

\section{NOTAS}

${ }^{1}$ A idéia de uma representação bimoraica de base também para ditongos nasais, que contraria a tradição trimoraica inaugurada por Câmara Jr.(1953), deriva da observação, já feita por Battisti (1997), de que a seqüência /VCN/ viola o padrão silábico máximo do português. O próprio autor, que explicava o glide nos ditongos nasais como um elemento homorgânico à vogal, aparentemente abandona essa idéia mais tarde, devido ao fato de /a/, por exemplo, combinar-se tanto com [w], como com [j]. 
${ }^{2}$ Uma decorrência da proposta é que, em final de vocábulo (armazém, cupim), não há vogais nasais. Todas as seqüências vN\# são interpretadas como ditongos.

${ }^{3}$ Prince \& Smolensky (op. cit.) salientam que a preocupação maior da Teoria da Otimidade é com as restrições e o modo como, interagindo, fazem emergir outputs através da avaliação de harmonia levada a cabo por Eval. A preocupação da Teoria da Otimidade com representações e operações é, assim, secundária, e a função Gen deve ser entendida apenas como um gerador de análises candidatas para dada forma de input, nada além disso.

${ }^{4}$ De acordo com Goldsmith (1990), a construção de uma tipologia de estrutura silábica para as línguas do mundo permite perceber que a coda apresenta um número menor de contrastes que o onset. $\mathrm{O}$ fato de, em português, a coda se restringir a glide, líquidas (segmentos que não contrastam por ponto de articulação), /s/ ou nasal homorgânica a consoante seguinte - Mauro, Marte, malte, mastro, manta-confirma essa idéia, levando à concepção da nasal, em nossa língua, como um segmento que tenha licenciado lexicalmente apenas o traço [nasal].

${ }^{5}$ Obligatory Contour Principle (Leben 1973), ou Princípio de Contorno Obrigatório, em português. O OCP proíbe ocorrências sucessivas da mesma especificação de traço.

${ }^{6}$ Embora, em português (cf. Cagliari 1977), a ocorrência de nasais homorgânicas antes de oclusivas não seja obrigatória, é o que geralmente se verifica nesse contexto. Uma terceira restrição talvez esteja em jogo nos poucos casos em que a nasal é apagada.

${ }^{7}$ Em final de palavra, segundo Cagliari (1997), todas as seqüências vN de input superficializam-se com nasal, exceto aN\#. Isso mostra que a preservação da consoante, e não seu apagamento, é a escolha do português.

${ }^{8}$ Palavras como bom são em número reduzido na língua. A maioria das palavras do grupo são empréstimos, e boa parte já está dicionarizada com a dupla possibilidade de pronúncia. Algumas, como guidão, já ocorrem mais que a forma com -oN, a mais aproximada do original (fr. guidon), inclusive com flexão -ões para o plural, como se dá com a maior parte dos vocábulos em -ão do português. 